\title{
Editorial: The Impact of Weather on the Behavior and Ecology of Birds
}

\author{
Mark C. Mainwaring ${ }^{1}$, Andreas Nord ${ }^{2}$ and Stuart P. Sharp ${ }^{3 *}$ \\ ${ }^{1}$ Division of Biological Sciences, University of Montana, Field Research Station at Fort Missoula, Missoula, MT, United States, \\ ${ }^{2}$ Section for Evolutionary Ecology, Department of Biology, Lund University, Lund, Sweden, ${ }^{3}$ Lancaster Environment Centre, \\ Lancaster University, Lancaster, United Kingdom
}

Keywords: birds, climate change, rainfall, reproduction, survival, temperature, weather, wind

Editorial on the Research Topic

The Impact of Weather on the Behavior and Ecology of Birds

\section{INTRODUCTION}

In recent times, research examining the effect of weather on birds has focused predominantly on the impact of climate change (Crick, 2004; Dunn and Winkler, 2010; Şekercioğlu et al., 2012; Riddell et al., 2021) or extreme weather events (e.g., Easterling et al., 2000; Bailey et al., 2017), often overlooking the fact that even small-scale variation in weather conditions can affect almost every aspect of avian biology. Short-term or localised changes in temperature, rainfall and wind can strongly influence individual behaviour, life history, physiology and morphology, with consequences at the population and species levels (e.g., McGowan et al., 2004; Wiley and Ridley, 2016). Further study of these processes is likely to play a key role in shaping our understanding of the mechanisms by which birds respond to climate change, but also has broader implications across

OPEN ACCESS

Edited and reviewed by: Jordi Figuerola,

Estación Biológica de Doñana (EBD), Spain

*Correspondence: Stuart P. Sharp

s.sharp2@lancaster.ac.uk

Specialty section:

This article was submitted to Behavioral and Evolutionary Ecology, a section of the journal

Frontiers in Ecology and Evolution

Received: 15 September 2021

Accepted: 28 September 2021

Published: 22 October 2021

Citation:

Mainwaring MC, Nord A and Sharp SP

(2021) Editorial: The Impact of

Weather on the Behavior and Ecology of Birds. Front. Ecol. Evol. 9:777478.

doi: 10.3389/fevo.2021.777478 ecology, evolution and conservation.

Birds are an ideal group in which to investigate the effects of weather because they occur in almost every ecosystem across the globe, they exploit a wide variety of food resources, and thousands of bird species migrate between vastly different environments during the course of their annual life cycle (Elkins, 1983; Both et al., 2006; Gordo, 2007). This Research Topic brings together articles from researchers across the globe who take a range of approaches to advance our understanding of the impact of weather on birds. The contributions take the form of original research papers, review papers that synthesise our understanding of topical issues or perspectives that highlight issues warranting further research attention. The articles cover three main aspects: (1) the influence of weather on birds during nest building and incubation; (2) the influence of weather on birds during offspring growth; and (3) the impact of weather on birds during the non-breeding season.

\section{IMPACT OF WEATHER ON BIRDS DURING NEST BUILDING AND INCUBATION}

Weather conditions impact the breeding ecology of birds, but a disproportionate amount of research attention has focused on the impacts of temperature rather than other weather variables, such as rainfall. Yet, rainfall impacts birds by influencing where (Fogarty et al., 2020) and when (Hidalgo et al., 2019) they breed. Rainfall also affects their reproductive output (Rodríguez and Bustamante, 2003; Skagen and Adams, 2012), for example by determining the foraging success of parents (Dawson and Bortolotti, 2000; Öberg et al., 2015). This Research Topic highlights 
that rainfall impacts birds in diverse ways, and Rosamond et al. show that Dickcissel (Spiza americana) populations decline with increasing amounts of summer rainfall. However, drought also influences the distribution of breeding birds (Barbaree et al., 2020; Campos-Cerqueira and Aide, 2021) and particularly so in arid regions (Herremans, 2004). Bourne et al. advance our understanding of adaptive responses to drought by showing that Southern Pied Babblers (Turdoides bicolor) in the Kalahari Desert in South Africa significantly reduce their reproductive effort during breeding seasons characterised by drought but subsequently increase their reproductive effort during the breeding seasons immediately following droughts. Birds may therefore adapt to drought by delaying their reproduction until the dry conditions have passed, and such lagged effects of weather conditions certainly deserve further attention.

The nest building and incubation stages of reproduction have lagged behind the offspring rearing stage in terms of the amount of research attention they have received (Hansell, 2000). Yet, it is now agreed that creating suitable microclimates in which to incubate eggs is important for embryos because temperatures that are higher or lower than optimal result in the mortality and suboptimal development of the embryos, respectively (McGowan et al., 2004; DuRant et al., 2012, 2013). In this Research Topic, we address this imbalance in research effort with a number of articles focusing on the nest and egg stages of reproduction. Specifically, Lowney et al. show that the extremely large communal nests of Sociable Weavers (Philetairus socius) provide year-round protection from adverse weather conditions in South Africa, whilst Perez et al. provide a comprehensive review of the influence of weather conditions on the morphology of birds' nests.

Other studies in the Research Topic address the effects of weather on breeding phenology. Hoover and Schelsky and McGuire et al. show that Prothonotary Warblers (Protonotaria citrea) and Arctic breeding waders, respectively, lay eggs earlier in warmer springs. Further, Huchler et al. show that the link between temperature and egg-laying phenology varies with the degree of urbanisation in Eurasian Kestrels (Falco tinnunculus), whilst Bründl et al. show that the link between temperature and phenology varies with altitude in Blue Tits (Cyanistes caeruleus). Nilsson et al. examine the influence of fine-scale variation in weather conditions on fecundity and show that White-throated Dippers (Cinclus cinclus) lay smaller clutch sizes in warmer temperatures. Elsewhere, Higgot et al. show that the incubation periods of Long-tailed Tits (Aegithalos caudatus) were longer in summers with higher amounts of rainfall. The amount of rainfall is expected to change over time (Trenberth et al., 2003) and so this study helps us better understand the impacts of rainfall on birds in a changing climate.

\section{IMPACT OF WEATHER ON BIRDS DURING OFFSPRING GROWTH}

Weather conditions impact the growth of offspring (Mainwaring and Hartley, 2016), both directly via effects on cooling the young (Ardia et al., 2010) and indirectly by influencing the provisioning behaviours of the parents (Wiley and Ridley, 2016; Nord and Nilsson, 2019). In this Research Topic, Sauve et al. provide a comprehensive review of these processes and suggest ways to improve evolutionary predictions, whilst de Zwaan et al. show contrasting effects of weather on growth in three alpine songbirds. Finally, Andreasson et al. highlight those issues that require further research attention if we are to increase our understanding of the impact of temperature on offspring growth. This is important because negative impacts experienced during growth often have long-lasting effects on individuals through to adulthood (Nord and Giroud, 2020).

\section{IMPACT OF WEATHER ON BIRDS DURING THE NON-BREEDING SEASON}

Birds are also impacted by weather during the non-breeding season and on migration. Those species living at high latitudes in the northern hemisphere may struggle to survive the cold winter months (Haftorn, 1972; Wolf and Hainesworth, 1972; Spencer, 1982), when the short, cold days barely provide sufficient time for small birds to forage and acquire enough energy to avoid starvation, and the low temperatures increase the energetic cost of staying warm (Brodin, 2007; Krams et al., 2010). Whilst some passerines save energy by occupying cavities that provide them with shelter from the cold night sky (Mainwaring, 2011), Boyer and MacDougall-Shackleton show experimentally that Whitethroated Sparrows (Zonotrichia albicollis) increased their fat levels in response to exposure to a hypobaric climatic wind tunnel that simulated winter storms.

Migratory species are susceptible to changing weather conditions at multiple stages of their journey and must time their movements accordingly (Haest et al., 2020). Here, Carneiro et al. examine the migratory behaviour of Whimbrels (Numenius phaeopus islandicus) in relation to temperature and winds, and Manola et al. use radar data to examine the intensity of migration over the North Sea in relation to synoptic weather conditions. Intense nights of migration were associated with an absence of rainfall and the presence of strong tailwinds, illustrating that sophisticated technological approaches can be used to examine the migratory behaviour of birds at large spatial scales.

\section{CONCLUSIONS}

The papers included in this Research Topic describe studies performed on several continents and increase our understanding of the impacts of weather on birds. We have included papers that explore exciting new topics such as the linkages between weather and the phenology of birds along gradients of urbanisation, the lagged effects of weather upon breeding birds and how birds may mitigate the negative impacts of drought by delaying their reproduction until the following breeding season. These studies have implications for our understanding of climate change because we can only accurately predict how birds may be affected by change if we have a sound understanding of how they are impacted by more typical weather conditions. We hope that the 
papers included in this Research Topic will spur many further studies that increase our understanding of the impact of weather on the behaviour and ecology of birds.

\section{AUTHOR CONTRIBUTIONS}

MM drafted the editorial. AN and SS edited the draft. All authors approved the final version for publication.

\section{FUNDING}

AN was supported by the Birgit and Hellmuth Hertz Foundation/The Royal Physiographic Society of Lund (2017-39034) and the Swedish Research Council (2020-04686).

\section{ACKNOWLEDGMENTS}

This Research Topic was inspired, in part, by a symposium on the effects of weather on birds that we organised during the 12th European Ornithologists' Union (EOU) Conference in Cluj Napoca, Romania in 2019. We are grateful to the EOU for hosting the symposium, and to the speakers and attendants for spurring us to initiate this Research Topic. Meanwhile, we are grateful to each of the authors for contributing papers to this special issue. We also thank all of the reviewers for providing their valuable time and insights, because their input considerably strengthened the quality of the manuscripts. Finally, we would like to thank Pamela Hohl, Rui Fernandes, and Helen Kimbell for their helpful guidance throughout the preparation of this Research Topic.

\section{REFERENCES}

Ardia, D. R., Pérez, J. H., and Clotfelter, E. D. (2010). Experimental cooling during incubation leads to reduced innate immunity and body condition in nestling tree swallows. Proc. Royal Soc. B 277, 1881-1888. doi: 10.1098/rspb.200 9.2138

Bailey, L., Ens, B., Both, C., Heg, D., Oosterbeek, K., and van de Pol, M. (2017). Phenotypic plasticity in nest-site selection as a response to extreme flooding events. Philos. Trans. R. Soc. Lond. B 372:20160139. doi: 10.1098/rstb.20 16.0139

Barbaree, B. A., Reiter, M. E., Hickey, C. M., Strum, K. M., Isola, J. E., Jennings, S., et al. (2020). Effects of drought on the abundance and distribution of non-breeding shorebirds in central California, USA. PLoS ONE 15:e0240931. doi: 10.1371/journal.pone. 0240931

Both, C., Bouwhuis, S., Lessells, C. M., and Visser, M. E. (2006). Climate change and population declines in a long-distance migratory bird. Nature 441, 81-83. doi: 10.1038/nature04539

Brodin, A. (2007). Theoretical models of adaptive energy management in small wintering birds. Philos. Trans. R. Soc. Lond. B 362, 1857-1871. doi: 10.1098/rstb.2006.1812

Campos-Cerqueira, M., and Aide, T. N. (2021). Impacts of a drought and hurricane on tropical bird and frog distributions. Ecosphere 12:e03352. doi: $10.1002 /$ ecs 2.3352

Crick, H. Q. P. (2004). The impact of climate change on birds. Ibis 146, 48-56. doi: 10.1111/j.1474-919X.2004.00327.x

Dawson, R. D., and Bortolotti, G. R. (2000). Reproductive success of American kestrels: the role of prey abundance and weather. Condor 102, 814-822. doi: 10.1093/condor/102.4.814

Dunn, P. O., and Winkler, D. W. (2010). "Effects of climate change on timing of breeding and reproductive success in birds" in Effects of Climate Change on Birds, eds A. P. Møller, W. Fieldler, and P. Berthold (Oxford: Oxford University Press), 113-128.

DuRant, S. E., Hopkins, W. A., Walters, J. R., and Hepp, G. R. (2013). Ecological, evolutionary, and conservation implications of incubation temperaturedependent phenotypes in birds. Biol. Rev. 88, 499-509. doi: 10.1111/br v. 12015

DuRant, S. E., Hopkins, W. A., Wilson, A. F., and Hepp, G. R. (2012). Incubation temperature affects the metabolic cost of thermoregulation in a young precocial bird. Funct. Ecol. 26, 416-422. doi: 10.1111/j.1365-2435.2011.0 1945.x

Easterling, D. R., Meehl, G. A., Parmesan, C., Changnon, S. A., Karl, T. R., and Mearns, L. O. (2000). Climate extremes: observations, modeling, and impacts. Science 289, 2068-2074. doi: 10.1126/science.289.5487.2068

Elkins, N. (1983). Weather and bird behaviour. London: T \& AD Poyser.

Fogarty, F. A., Cayan, D. R., DeHaan, L. L., and Fleishman, E. (2020). Associations of breeding-bird abundance with climate vary among species and trait-based groups in southern California. PLOS ONE 15:e0230614. doi: 10.1371/journal.pone.0230614

Gordo, O. (2007). Why are bird migration dates shifting? A review of weather and climate effects on avian migratory phenology. Clim. Res. 35, 37-58. doi: $10.3354 / \mathrm{cr} 00713$

Haest, B., Hüppop, O., and Bairlein, F. (2020). Weather at the winter and stopover areas determines spring migration onset, progress, and advancements in Afro-Palearctic migrant birds. Proc. Natl. Acad. Sci. U.S.A. 117, 17056-17062. doi: $10.1073 /$ pnas. 1920448117

Haftorn, S. (1972). Hypothermia of tits in the arctic winter. Ornis Scand. 3, 153-166. doi: $10.2307 / 3676222$

Hansell, M. H. (2000). Bird Nests and Construction Behaviour. Cambridge: Cambridge University Press. doi: 10.1017/CBO9781139106788

Herremans, M. (2004). Effects of drought on birds in the Kalahari, Botswana. Ostrich 75, 217-227. doi: 10.2989/00306520409485448

Hidalgo, A. N., Hall, M. L., Kingma, S. A., van de Pol, M., and Peters, A. (2019). Rapid plastic breeding response to rain matches peak prey abundance in a tropical savanna bird. J. Anim. Ecol. 88, 1799-1811. doi: 10.1111/1365-2656.13068

Krams, I., Cirule, D., Suraka, V., Krama, T., Rantala, M. J., and Ramey, G. (2010). Fattening strategies of wintering great tits support the optimal body mass hypothesis under conditions of extremely low ambient temperature. Funct. Ecol. 24, 172-177. doi: 10.1111/j.1365-2435.2009.01628.x

Mainwaring, M. C. (2011). The use of nestboxes by roosting birds during the non-breeding season: a review of the costs and benefits. Ardea 99, 167-176. doi: 10.5253/078.099.0206

Mainwaring, M. C., and Hartley, I. R. (2016). Local weather conditions have complex effects on the growth of blue tit nestlings. J. Therm. Biol. 60, 12-19. doi: 10.1016/j.jtherbio.2016.05.005

McGowan, A., Sharp, S. P., and Hatchwell, B. J. (2004). The structure and function of nests of long-tailed tits Aegithalos caudatus. Funct. Ecol. 18, 578-583. doi: 10.1111/j.0269-8463.2004.00883.x

Nord, A., and Giroud, S. (2020). Lifelong effects of thermal challenges during development in birds and mammals. Front. Physiol. 11:419. doi: $10.3389 /$ fphys.2020.00419

Nord, A., and Nilsson, J. (2019). Heat dissipation rate constrains reproductive investment in a wild bird. Funct. Ecol. 33, 250-259. doi: 10.1111/1365-2435.13243

Öberg, M., Arlt, D., Pärt, T., Laugen, A. T., Eggers, S., and Low, M. (2015). Rainfall during parental care reduces reproductive and survival components of fitness in a passerine bird. Ecol. Evol. 5, 345-356. doi: 10.1002/ece 3.1345 
Riddell, E. A., Iknayan, K. J., Hargrove, L., Tremor, S., Patton, J. L., Ramirez, R., et al. (2021). Exposure to climate change drives stability or collapse of desert mammal and bird communities. Science 371, 633-636. doi: 10.1126/science.abd4605

Rodríguez, C., and Bustamante, J. (2003). The effect of weather on lesser kestrel breeding success: can climate change explain historical population declines? J. Anim. Ecol. 72, 793-810. doi: 10.1046/j.1365-2656.2003.0 0757.x

Şekercioğlu, C.. H., Primack, R. B., and Wormworth, J. (2012). The effects of climate change on tropical birds. Biol. Cons. 148, 1-18. doi: 10.1016/j.biocon.2011.10.019

Skagen, S. K., and Adams, A. A. Y. (2012). Weather effects on avian breeding performance and implications of climate change. Ecol. Appl. 22, 1131-1145. doi: 10.1890/11-0291.1

Spencer, R. (1982). Birds in winter-an outline. Bird Study 29, 169-182. doi: $10.1080 / 00063658209476754$

Trenberth, K. E., Dai, A., Rasmussen, R. M., and Parsons, D. B. (2003). The changing character of precipitation. Bull. Am. Meteorol. Soc. 84, 1205-1217. doi: 10.1175/BAMS-84-9-1205

Wiley, E. M., and Ridley, A. R. (2016). The effects of temperature on offspring provisioning in a cooperative breeder. Anim. Behav. 117, 187-195. doi: 10.1016/j.anbehav.2016.05.009
Wolf, L. L., and Hainesworth, F. R. (1972). Environmental influence on regulated body temperature in torpid hummingbirds. Comp. Biochem. Physiol. B 41, 167-173. doi: 10.1016/0300-9629(72)90044-8

Conflict of Interest: The authors declare that the research was conducted in the absence of any commercial or financial relationships that could be construed as a potential conflict of interest.

Publisher's Note: All claims expressed in this article are solely those of the authors and do not necessarily represent those of their affiliated organizations, or those of the publisher, the editors and the reviewers. Any product that may be evaluated in this article, or claim that may be made by its manufacturer, is not guaranteed or endorsed by the publisher.

Copyright (๑) 2021 Mainwaring, Nord and Sharp. This is an open-access article distributed under the terms of the Creative Commons Attribution License (CC BY). The use, distribution or reproduction in other forums is permitted, provided the original author(s) and the copyright owner(s) are credited and that the original publication in this journal is cited, in accordance with accepted academic practice. No use, distribution or reproduction is permitted which does not comply with these terms. 